\title{
Molusco contagioso
}

\author{
Molluscum contagiosum
}

\section{Gerzaín Rodríguez¹, Dayana Arenas²}

1. Médico dermatopatólogo; profesor, Facultad de Medicina, Universidad de La Sabana, Chía, Colombia; docente, Hospital Universitario Dermatológico Federico Lleras Acosta E.S.E., Bogotá, D.C., Colombia

2. Residente de Dermatología, Fundación Universitaria Sanitas, Bogotá, D.C., Colombia

\section{RESUMEN}

El molusco contagioso afecta entre el 5 y el $16 \%$ de los niños menores de 16 años, principalmente aquellos con dermatitis atópica. Es frecuente en pacientes inmunosuprimidos, especialmente aquellos con sida. Se manifiesta como pápulas eucrómicas, umbilicadas, pequeñas, localizadas frecuentemente en la cara y los pliegues. Se transmite por contacto directo con la piel o por fómites y, en los niños, se presenta autoinoculación. En pacientes con sida, las lesiones pueden alcanzar gran número y tamaño, y ser de mayor duración y recurrentes.

El diagnóstico es clínico, pero en casos de duda, el frotis directo o la biopsia son concluyentes. El tratamiento del molusco contagioso es diverso y depende de la experiencia de cada profesional.

El objetivo de esta revisión de tema es recordar las principales características de esta infección, algunas propiedades del virus y su desarrollo en los queratocitos epidérmicos. También, se hace un resumen de las principales opciones terapéuticas disponibles para su manejo.

PALABRAS CLAVE: molusco contagioso, infecciones por poxvirus, niños, inmunosupresión.

\section{SUMMARY}

Molluscum contagiosum infection affects between 5 and $16 \%$ of children under 16 years of age, especially those with atopic dermatitis. It is common in immunosuppressed patients, especially those with AIDS. It manifests as flesh tone papules, umbilicated, small in size, frequently located in the face and body folds. Its transmission occurs by direct contact with the skin or through fomites. In children, it is self-induced. In patients with AIDS, lesions can be greater in number and size as well as recurrent.

The diagnosis is made by clinical observation, but in uncertain cases the direct smear or the biopsy are conclusive. There are several treatment options; it depends on the clinical experience of each physician.

This review focuses on the main characteristics of this infection, exposing some properties of the virus and its development within epidermal keratino-

\author{
Correspondencia: \\ Gerzaín Rodríguez \\ Dayana Arenas \\ Email: \\ josert@unisabana.edu.co \\ diarenasaya@gmail.com \\ Recibido: 28/04/2017 \\ Aceptado: 20/07/2017 \\ Conflictos de interés: \\ No se reportan conflictos de \\ interés. \\ Financiación: \\ Ninguna.
}


cytes. We summarize the main therapeutic approaches available for the management of these patients.

KEY WORDS: Molluscum contagiosum, poxviridae infections, child, immunosuppression.

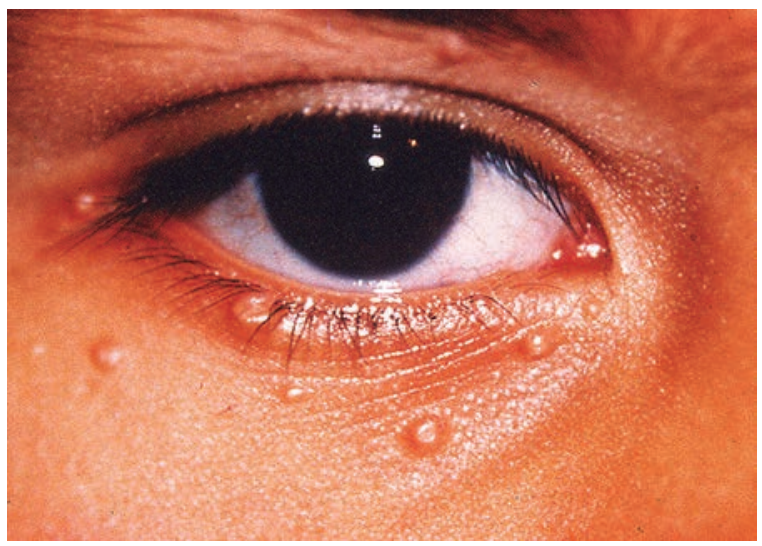

Figura 1. Pápulas palpebrales amarillentas y con discreta umbilicación

\section{INTRODUCCIÓN}

Las pápulas amarillentas con discreta umbilicación central es la presentación característica del molusco contagioso, una enfermedad viral cutánea que afecta entre el 5 y el $16 \%$ de los niños menores de 16 años y a las personas inmunosuprimidas, entre ellas, del 5 al $30 \%$ de los pacientes con sida ${ }^{(1-3)}$. En la figura 1 se ilustran estas lesiones palpebrales en un niño. Predomina en climas tropicales, en niños de 1 a 4 años de edad, en aquellos con dermatitis atópica y en los que frecuentan piscinas ${ }^{(1-4)}$. El agente causal es el virus del molusco

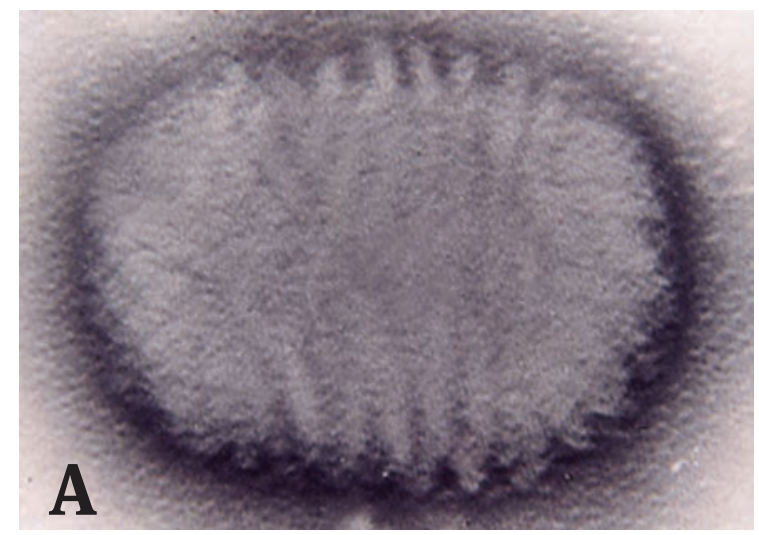

contagioso (tipos 1, 2, 3, y 4) ${ }^{(5)}$, un poxvirus o virus vesicular del género Molluscipoxvirus. Entre los virus pox están el de la vaccinia (vacuna contra la viruela, que erradicó la enfermedad en el mundo), el de la viruela, el del Orf y el del nódulo de los ordeñadores ${ }^{(477)}$. Son los virus conocidos de mayor tamaño (300 x 210 $\mathrm{nm}$, en promedio), con forma de ladrillo (figura 2), que se desarrollan en el citoplasma de los queratocitos epidérmicos (figuras 3, 4). Tienen un nucleoide central en forma de "8", que es el ADN de doble cadena, rodeado de una cápside compleja y cubierto por una envoltura trilaminar (figura 2B) ${ }^{(1,6)}$.

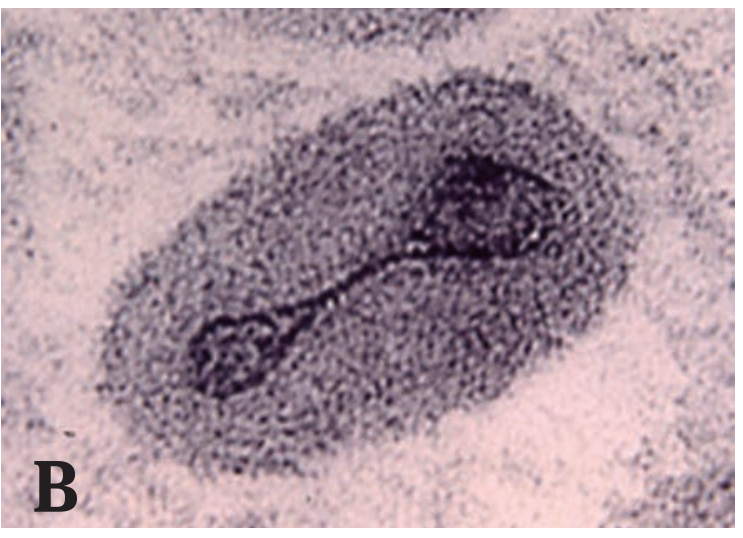

Figura 2. Virus del molusco contagioso visto al microscopio electrónico, con tinción negativa y con cortes convencionales. Resaltan su genoma en forma de 8, la cápside y su envoltura. 

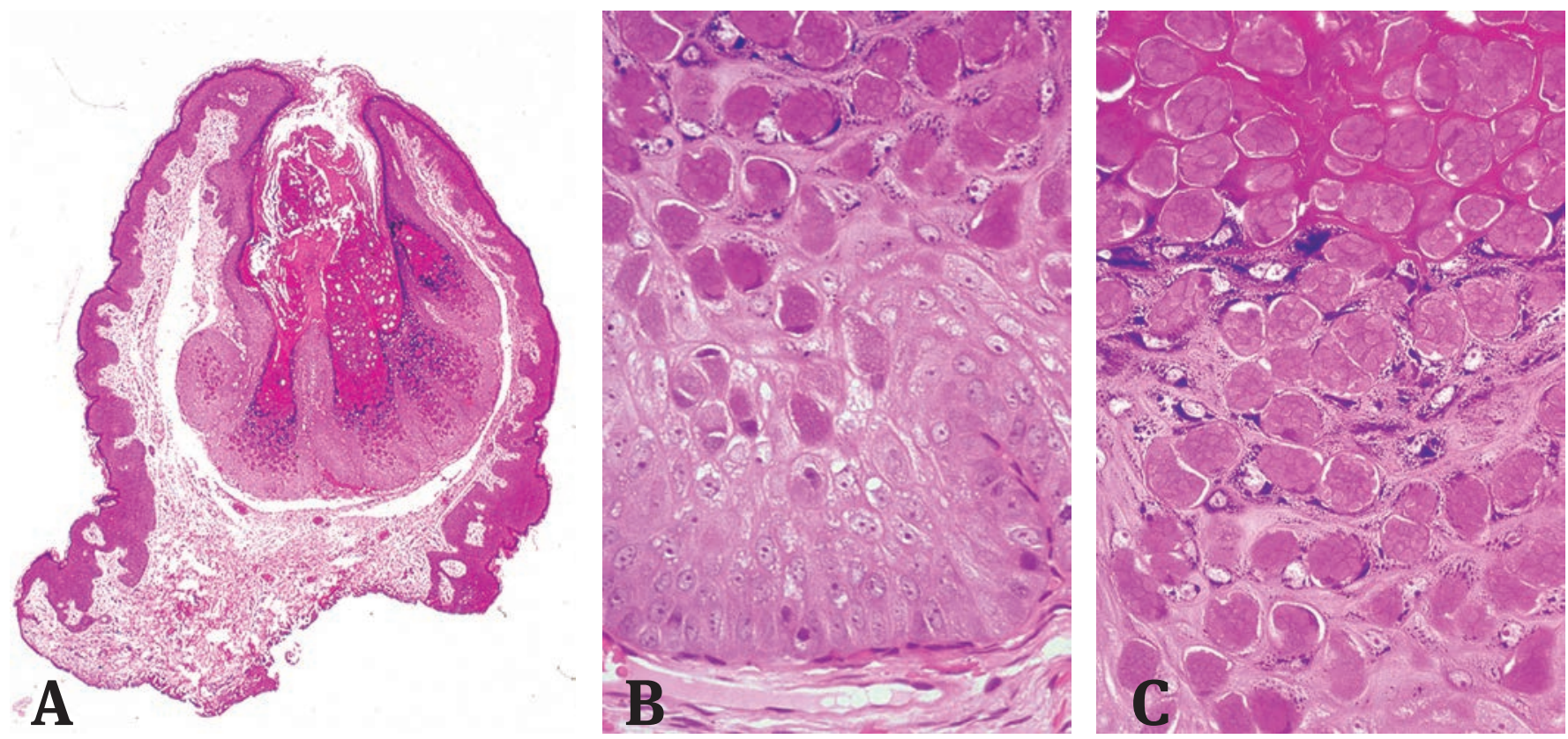

Figura 3. A. La pápula está constituida por epidermis acantósica que se proyecta hacia la dermis, con centro queratósico abierto al exterior. Nótese la dermis sin inflamación. Hematoxilina y eosina, $3 \mathrm{X}$.

Figura 3. B y C. Los queratocitos albergan inclusiones citoplásmicas eosinofílicas, aparentes desde las células suprabasales, que rechazan el núcleo hacia la periferia celular y se observa como una estructura oblonga, delgada y basófila. Hematoxilina y eosina, 40X.

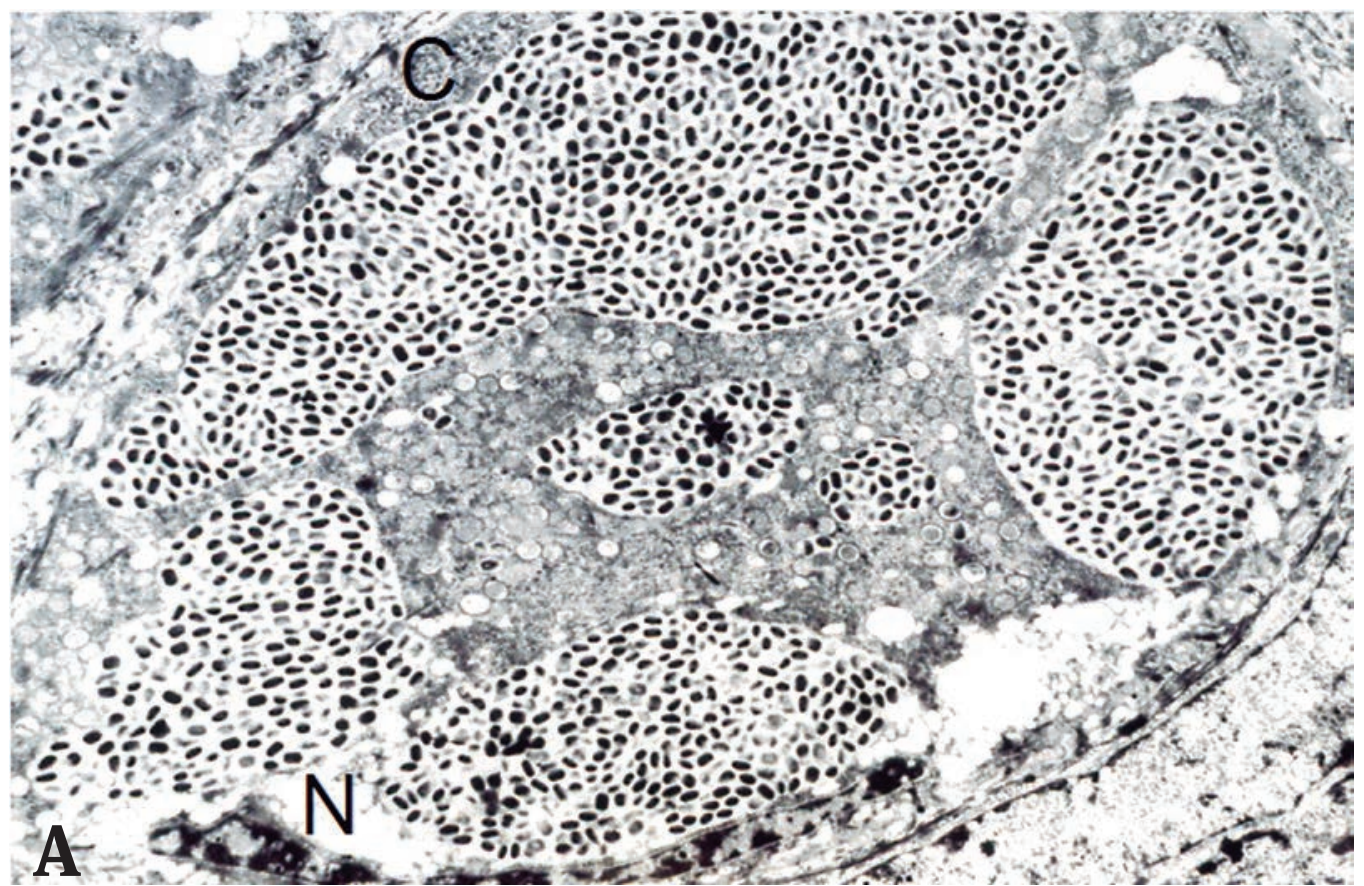

Figura 4. A. Célula malpighiana repleta de partículas virales. El centro celular tiene una masa ramificada ocupada por material granular fino y partículas redondeadas, claras, que corresponden a virus en formación. Cuando maduran, se depositan en las masas de virus densos, que comprimen el citoplasma (C) y el núcleo (N). La célula está totalmente dedicada a la síntesis viral, 10.00oX. 


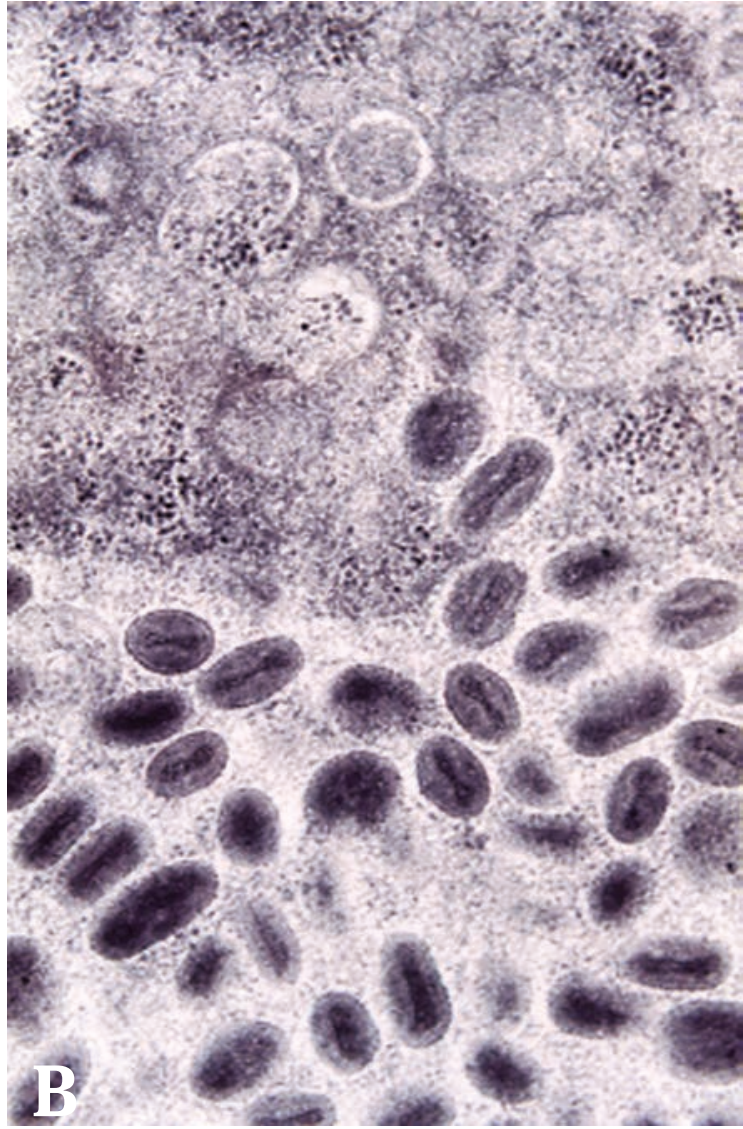

Figura 4. B. A mayor aumento se aprecia el área de síntesis viral, con partículas claras, cubiertas por una membrana trilaminar (arriba), que al condensarse y madurar se depositan en conglomerados citoplásmicos 40 oooX. Reproducidas con permiso del Instituto Nacional de Salud: Rodríguez G. Microscopía electrónica de la infección viral. Bogotá: Instituto Nacional de Salud; 1983. p. 99 y 101.

En la biopsia de la lesión se observa una pápula constituida por epidermis acantósica, con queratocitos voluminosos, de citoplasma eosinófilo y núcleo rechazado hacia la periferia, adelgazado y comprimido por 'fábricas' de virus, que llegan a ocupar la mayor parte del citoplasma (figuras 3 y 4). El desarrollo viral comienza en la capa basal de la epidermis y paulatinamente aumenta, formando masas citoplásmicas granulares o densas, que representan sitios de síntesis viral ${ }^{(4,5)}$. Los virus aparecen primero como estructuras redondeadas, envueltas por una membrana que se va condensando hasta formar viriones típicos y característicos (figura 4). Las células granulosas altas y los corneocitos terminan siendo masas virales con escaso citoplasma original (figuras 4 y 5). La masa central de células córneas llenas de virus constituye la umbilicación central típica de la lesión. Su descamación va a contaminar otras áreas cutáneas del huésped o a otros pacientes. Esta abundancia y la liberación viral explican por qué el molusco contagioso es de fácil y amplia transmisión.

En la biopsia (figura 3), son aparentes la ausencia de inflamación dérmica y la capacidad viral para evadir al sistema inmunológico y evitar su eliminación, mediante la producción de proteínas virales, como el análogo de la quimiocina, que inhibe la reacción inflamatoria, el análogo de la peroxidasa del glutatión, que protege la célula infectada del daño por oxidación por los peroxisomas, y el inhibidor de la caspasa 8, que disminuye la apoptosis secundaria al 'ligador' FAS y al TNF-alfa ${ }^{(8)}$. El virus no induce necrosis apoptósica de los queratocitos, lo cual destruiría la célula en la cual se multiplica ${ }^{(8)}$. Por esta razón, en general, el molusco contagioso es una infección crónica que cura espontáneamente en tres a nueve meses, pero que puede persistir por dos o tres años ${ }^{(2)}$.

El paciente nuevo se infecta por contacto directo, piel a piel, con otro paciente o mediante fómites, que son los objetos inanimados capaces de albergar y transmitir el virus, tales como toallas, pañuelos, cepillos, peines o ropas. El molusco contagioso también es una enfermedad de transmisión sexual. Las lesiones en los genitales de niños pueden ocurrir por autoinoculación, sin embargo, siempre debe investigarse la posibilidad de abuso sexual (figura 6) ${ }^{(1)}$.

El virus de tipo I produce el $98 \%$ de las lesiones del molusco, y el de tipo II se presenta solo en adultos, no en niños, asimismo, en pacientes con sida, y es de transmisión sexual ${ }^{(7)}$. Su tipificación requiere técnicas biomoleculares ${ }^{(7)}$.

Los pacientes pueden tener pocas o decenas de lesiones, que predominan en la cara, los pliegues antecubitales y las axilas. La afección conjuntival u oral es rara. La presencia de lesiones genitales y la de lesiones numerosas o voluminosas, debe hacer sospechar la posibilidad de sida (figura 7). En un estudio publicado en el 2009, se encontró una prevalencia de infección por HIV de 3,91\% entre 128 pacientes mayores de 18 años con diagnóstico de molusco contagioso. El 100\% de estos pacientes tenía lesiones faciales. Esta fue la prevalencia más alta entre todas las enfermedades estudiadas, seguida por la dermatitis seborreica (prevalencia de $2,05 \%)^{(9)}$.

El diagnóstico es usualmente fácil mediante el examen clínico, lo mismo que por la biopsia. El frotis directo, en fresco, suspendido en $\mathrm{KOH}$ o teñido con Giemsa, revela las típicas células del molusco (figura ${ }_{5} \mathbf{C}$ ). 

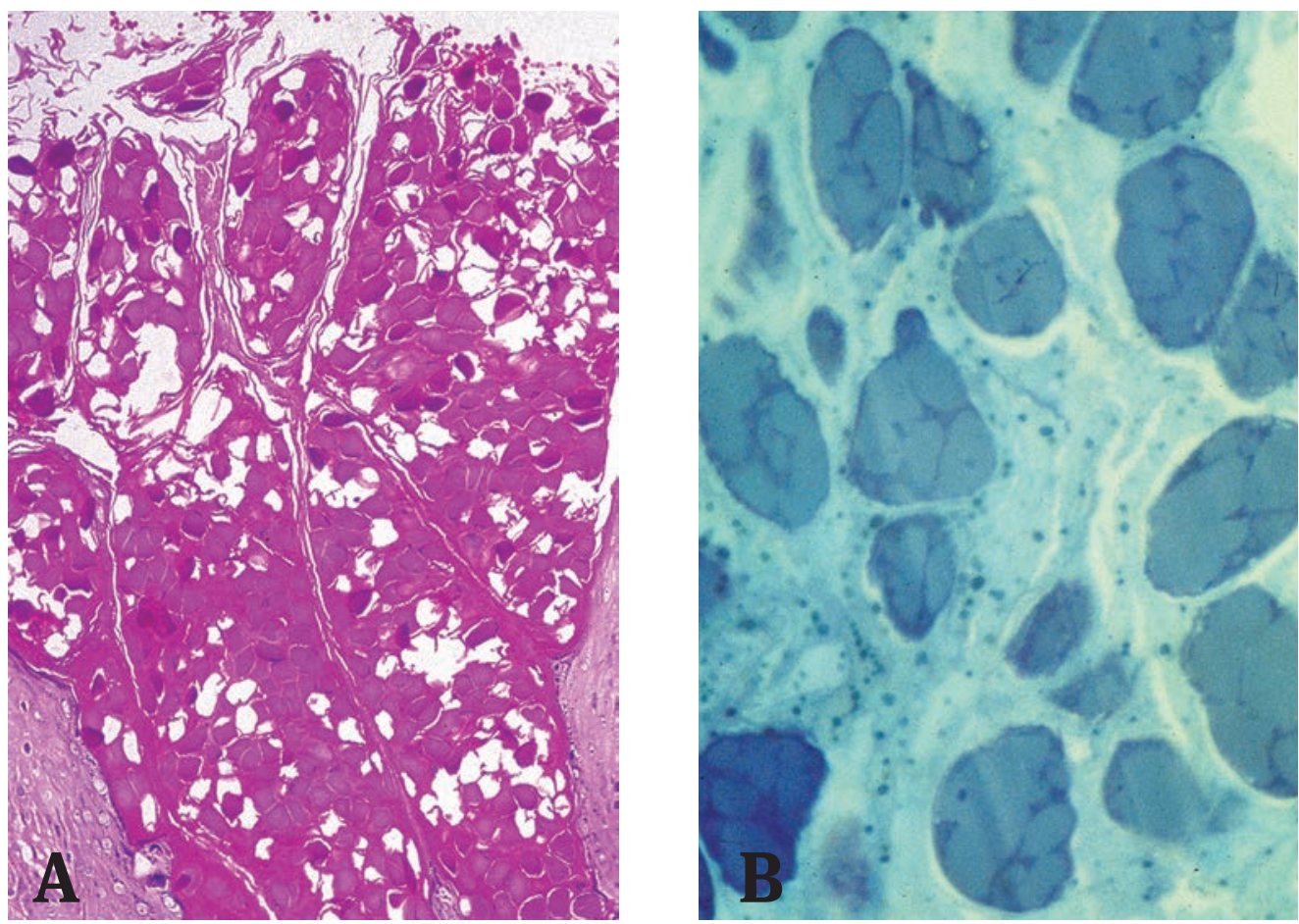

Figura 5. A. Células córneas del orificio central de la lesión, transformadas en cuerpos de molusco, llenas de virus. Hematoxilina y eosina, 16X.

Figura 5. B. En cortes de media micra de espesor, se aprecian las células córneas, voluminosas, con estrías azulosas, que son los sitios de síntesis viral, correspondientes al área central y ramificada de la figura 4A. Azul de toluidina, 100X.

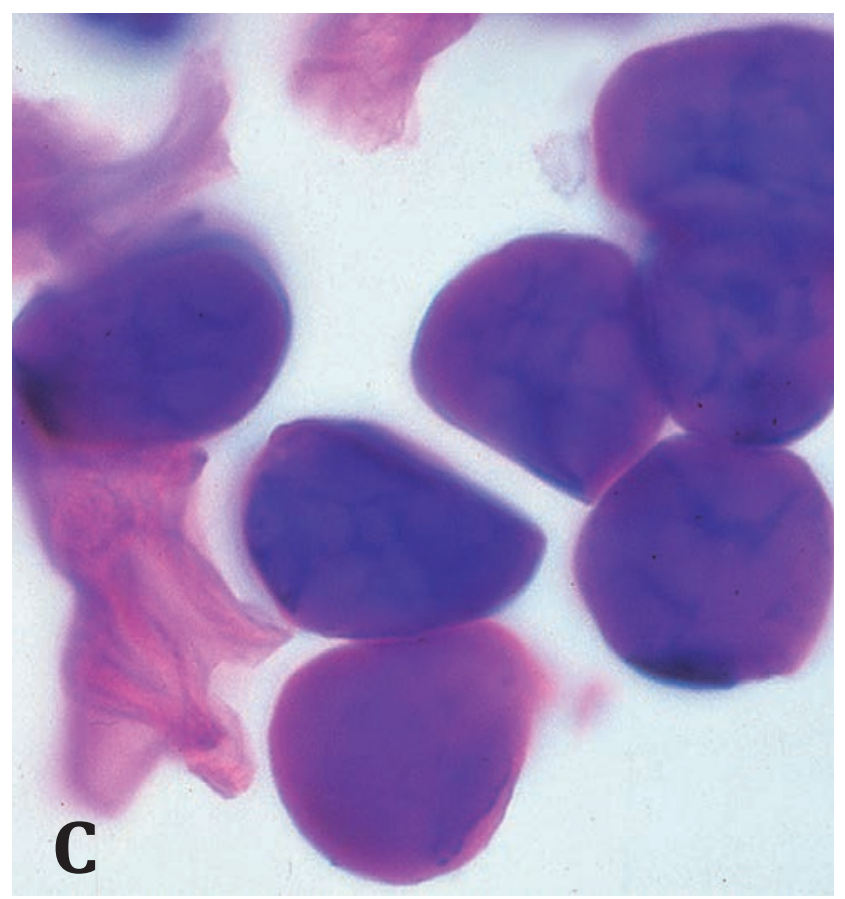

Figura 5. C. Un frotis directo de estas células, examinado con $\mathrm{KOH}$ al $10 \%$ o teñido con Giemsa, permite el diagnóstico inmediato al revelar las típicas células del molusco, con estrías citoplásmicas y núcleo comprimido, periférico. Giemsa, 100X. 


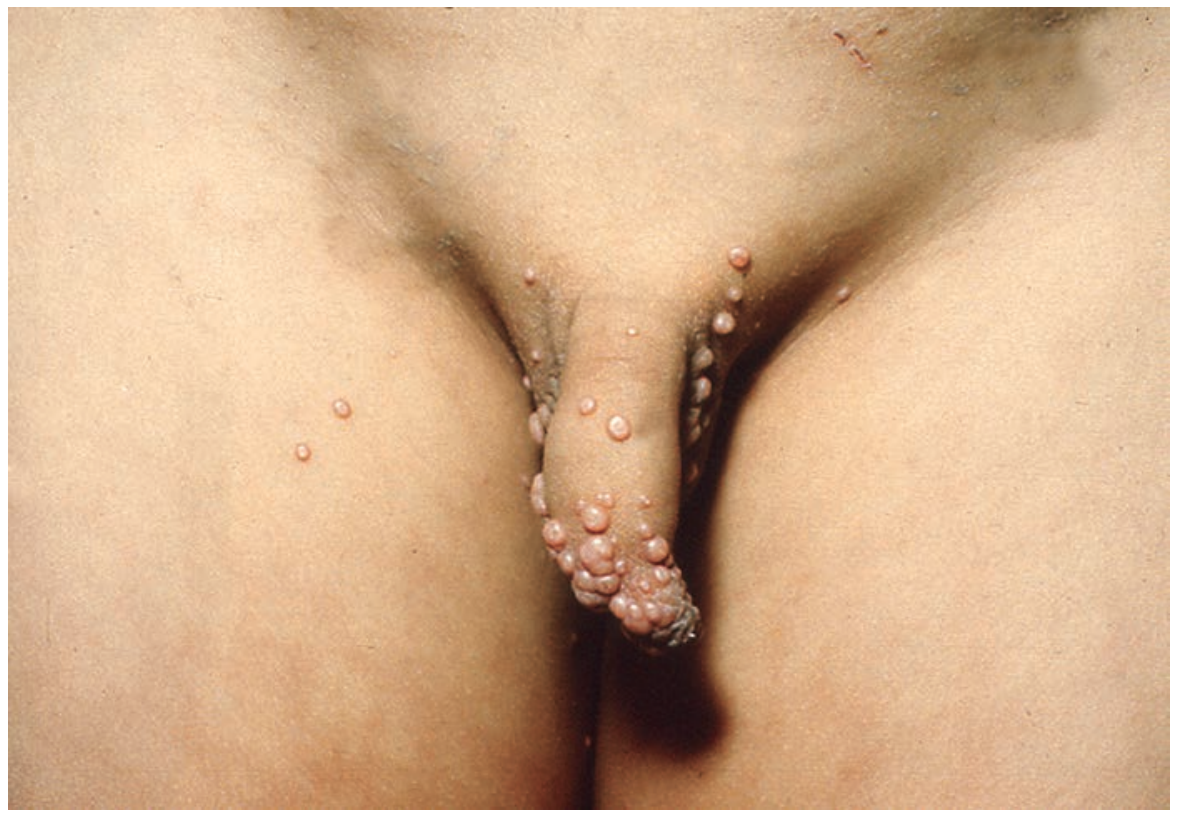

Figura 6. Niño con numerosas lesiones de molusco contagioso, peneanas e inguinales. Debe investigarse la posibilidad de abuso sexual.

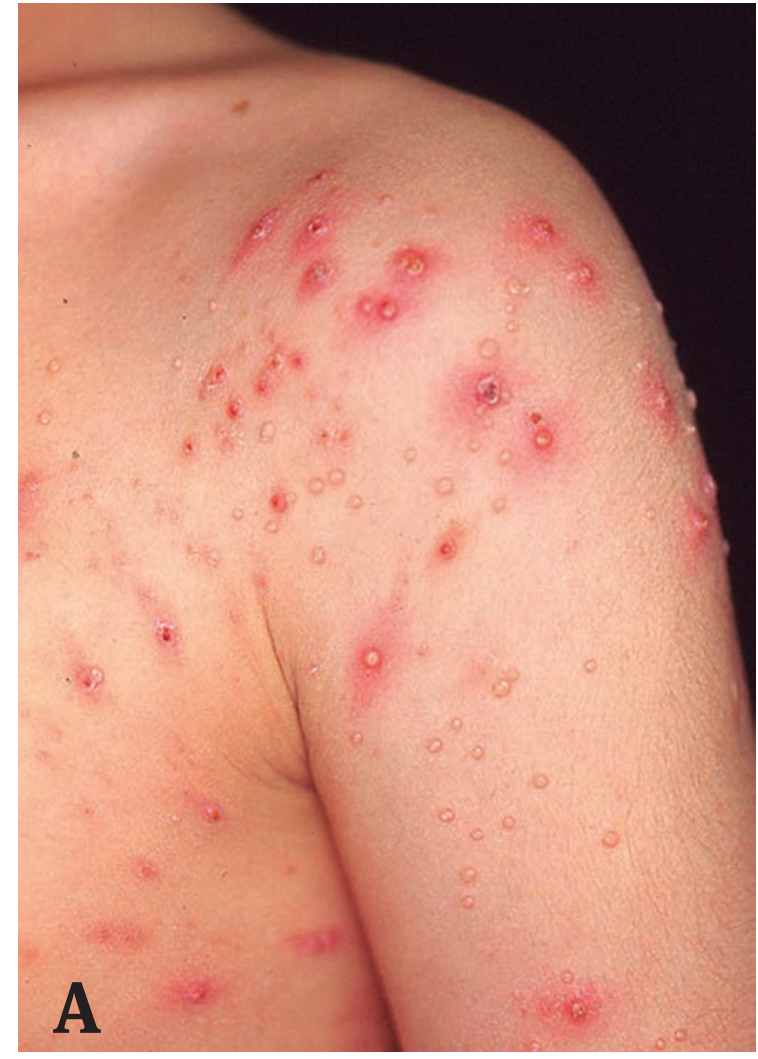

Figura 7. A. Hombre joven, positivo para HIV, con numerosas lesiones de molusco, algunas escoriadas o rodeadas de eritema.

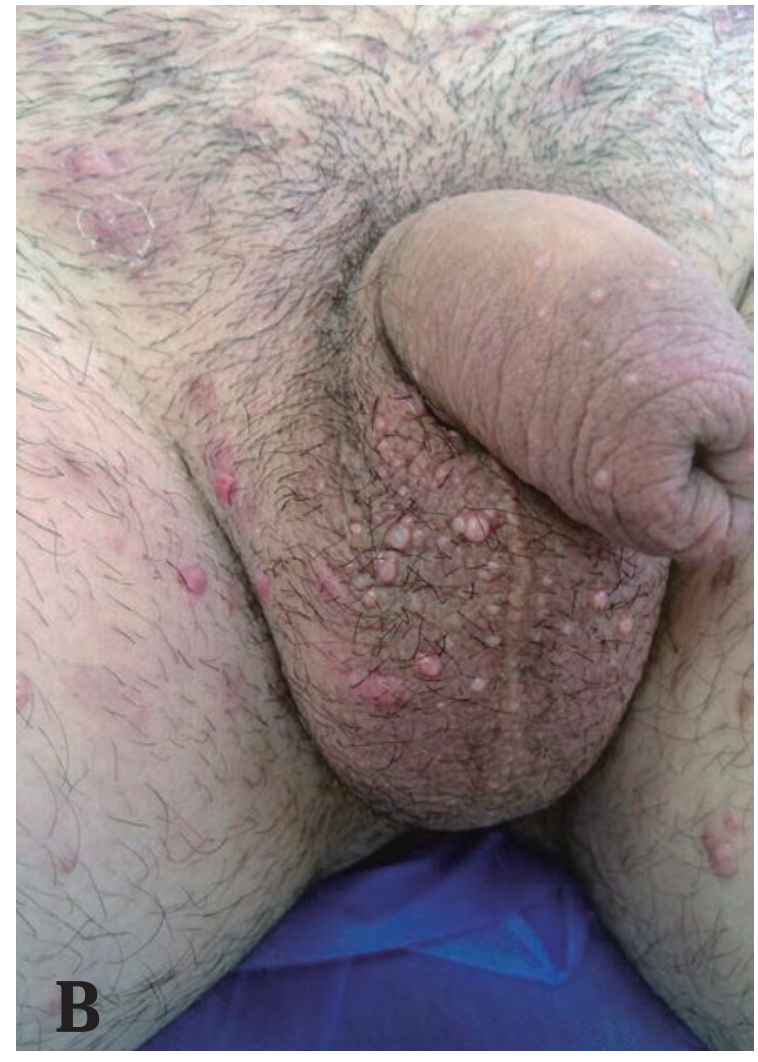

Figura 7. B. Paciente positivo para HIV con numerosas lesiones genitales, perineales y de la piel vecina. Fotografías por cortesía del doctor Ángel Jaimes 


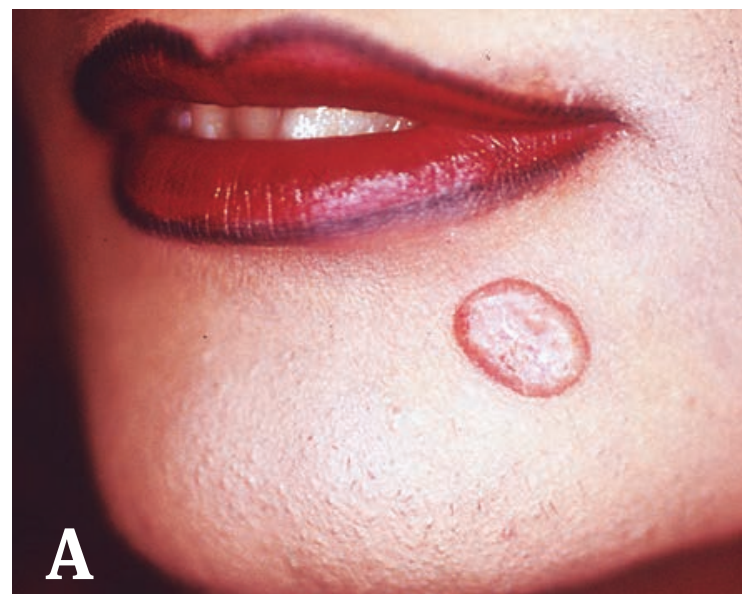

Figura 8. A. Pápula voluminosa de criptococosis en un paciente con sida.

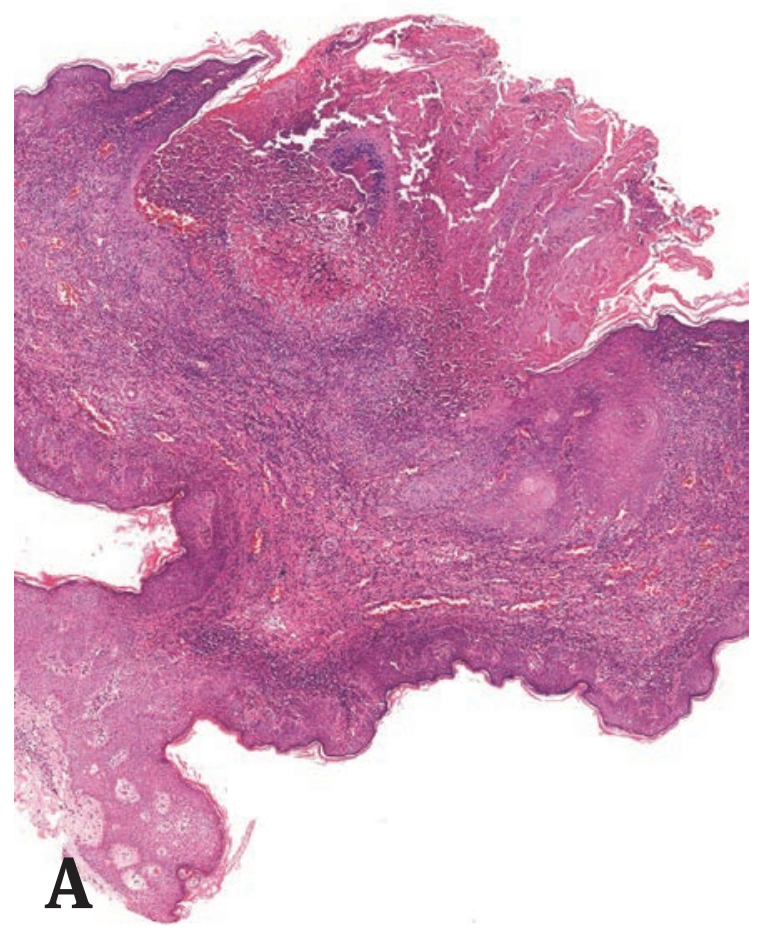

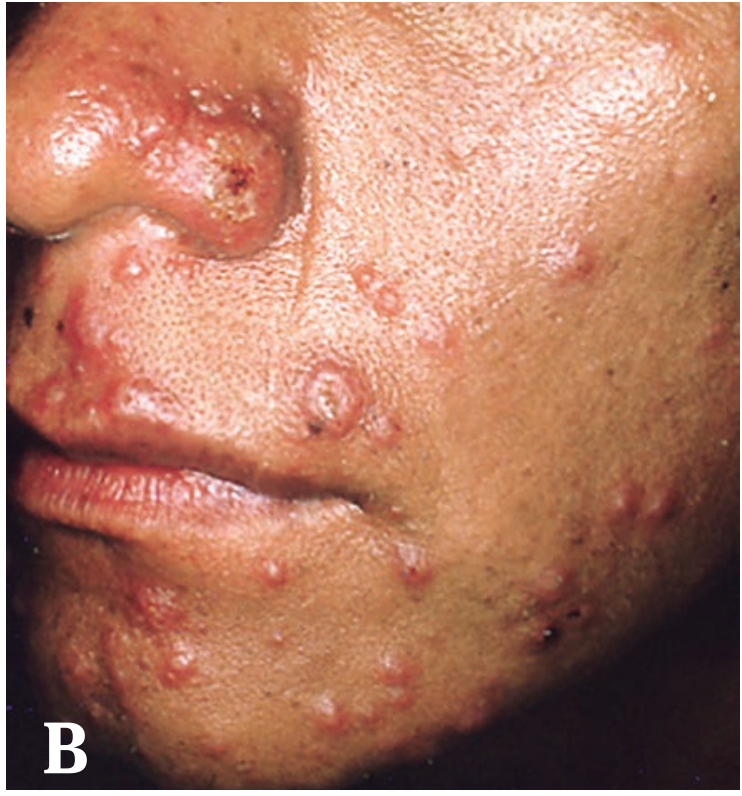

Figura 8. B. Pápulas umbilicadas en un paciente con sida e histoplasmosis diseminada.

Fotografías por cortesía de la doctora Adriana Motta.

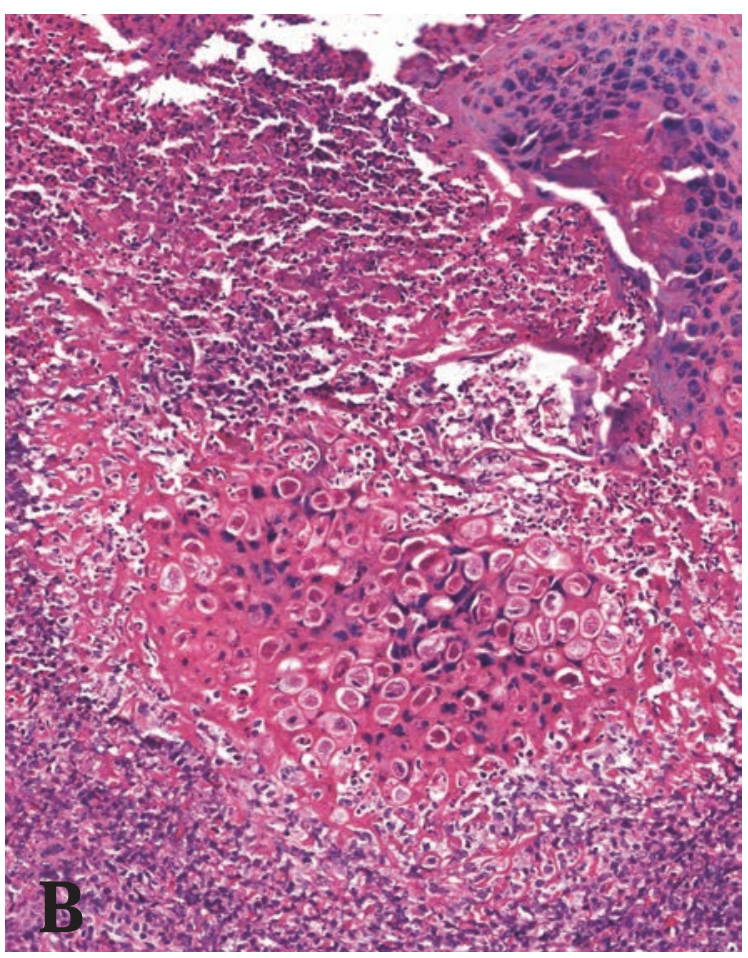

Figura 9. Molusco contagioso inflamatorio. A. Pápula ulcerada, cubierta por escamocostra y pústula, con inflamación dérmica notoria. Hematoxilina y eosina, $4 \mathrm{X}$.

B. A mayor aumento se reconocen las típicas inclusiones del molusco, rodeadas por la inflamación. Hematoxilina y eosina, 20X. 
Las variantes atípicas del molusco contagioso incluyen lesiones gigantes (mayores de $5 \mathrm{~mm}$ ), lesiones eccematosas y lesiones foliculocéntricas con formación secundaria de abscesos ${ }^{(10)}$. En estos casos, se recurre a las opciones diagnósticas mencionadas anteriormente.

Los diagnósticos diferenciales incluyen las verrugas planas, los condilomas acuminados, los siringomas, los xantogranulomas, el granuloma anular papuloso y los lepromas histioides, así como tumores di$\operatorname{versos}^{(1,4,11-12)}$. En los pacientes con sida, la criptococosis y la histoplasmosis diseminada pueden producir lesiones que semejan el molusco contagioso ${ }^{(6,13)}$ (figura 8A). Además, en ellos las lesiones pueden llegar a tener hasta $3 \mathrm{~cm}$ de diámetro (figura 8B). El frotis directo o la biopsia aclaran cualquier duda.

Algunas lesiones se pueden romper por trauma, rascado o de forma secundaria al tratamiento; desarrollan una reacción inflamatoria dérmica y generan el molusco contagioso inflamatorio, que puede originar un granuloma a cuerpo extraño, una inflamación eosinofílica con figuras en llama o una inflamación rica en linfocitos atípicos CD30 positivos, que puede confundirse con linfoma ${ }^{(14)}$. El hallazgo de las inclusiones típicas aclara el diagnóstico (figura 9).

El tratamiento del molusco contagioso es amplio, depende de la experiencia de cada profesional, y puede decirse que no existe un consenso sobre el mismo ${ }^{(15,16)}$. Entre las opciones más usadas, se encuentran los agentes químicos destructivos, como el ácido tricloroacético ${ }^{(16)}$, los agentes químicos no destructivos como la cantaridina ${ }^{(17,18)}$, la podofilotoxina, el ácido salicílico y el ácido retinoico ${ }^{(19)}$. Además, pueden utilizarse el raspado (curettage), la crioterapia ${ }^{(20)}$ o la luz pulsada, con resultados terapéuticos variables. También, se han ensayado inmunomoduladores locales, como el imiquimod tópico al $5 \%$, la inyección intralesional de antígeno de cándida, la cimetidina y la difenciprona ${ }^{(21)}$. Todos estos métodos pueden generar, en mayor o menor medida, efectos secundarios como irritación, edema, formación de ampollas y dolor, así como cicatrices, por lo cual se deben sopesar estos efectos con los resultados favorables (20). Para evitar la incomodidad durante el procedimiento, algunos dermatólogos practican el raspado de las lesiones bajo anestesia tópica o, en niños pequeños con abundantes lesiones, bajo anestesia general.

En algunos estudios también se reporta la utilidad de la terapia láser en las lesiones de molusco contagioso, con buenos resultados, teniendo en cuenta la edad del paciente, el número y la localización de las lesiones ${ }^{(20,22-23)}$.

En un estudio, se analizaron la eficacia y los efectos
"El tratamiento del molusco contagioso es amplio, depende de la experiencia de cada profesional, y puede decirse que no existe un consenso sobre el mismo ${ }^{(15,16)}$. Entre las opciones más usadas, se encuentran los agentes químicos destructivos, como el ácido tricloroacético."

secundarios de cuatro tratamientos en 124 niños ${ }^{(19)}$. Se evaluó la cantaridina, el raspado, la combinación de ácido salicílico con ácido láctico y el imiquimod. En los cuatro grupos hubo eficacia en el manejo de la infección, con resultados más favorables en el del raspado, que requirió menos consultas hasta la curación (80,6\% de los pacientes curados en la primera consulta) y tuvo un alto porcentaje de satisfacción $(86,7 \%)$ y el menor porcentaje de efectos secundarios (4,7 \%). El tratamiento con mayor número de efectos secundarios fue la combinación de ácido salicílico y ácido láctico (53,5\%), y tuvo el porcentaje más bajo de satisfacción $(32,1 \%)$. Los autores concluyeron que el manejo del molusco contagioso debe ser individualizado, según la edad del paciente, la tolerancia de los efectos secundarios, el número y la ubicación de las lesiones, y siempre debe estar concertado entre el dermatólogo y el paciente o sus padres ${ }^{(19)}$.

En el 2009, se publicó una revisión sistemática de la literatura (Cochrane) ${ }^{(20)}$, que incluyó 18 estudios con diversas opciones terapéuticas. Tenían muestras de tamaño pequeño, intervalos de confianza amplios y la mayoría no eran controlados con placebo, sino con alguna sustancia que pudo haber tenido un efecto terapéutico (aceite de oliva, solución salina o alcohol), por lo que fue difícil comparar el efecto neto de las intervenciones. Se concluyó que no es posible hacer una recomendación terapéutica, y que se deben llevar a cabo estudios sólidos que permitan hacer un enfoque más real del tratamiento de esta enfermedad.

En el tratamiento se debe tener en cuenta lo siguiente:

1. La inmunidad natural suprime la enfermedad en la mayoría de los niños, en tres a nueve meses ${ }^{(2)}$.

2. El virus produce proteínas que evitan la reacción inmunológica del huésped ${ }^{(8)}$.

3. La inmunidad natural logra que algunos pacientes 
tengan pocas lesiones, mientras que otros, aun sin inmunosupresión, pueden albergar decenas de ellas. "La inmunosupresión, como en el sida, permite la presencia de numerosas lesiones, en los genitales, los brazos y la cara, principalmente (figura 7); las lesiones pueden ser voluminosas, hasta de $3 \mathrm{~cm}$ de diámetro, resistentes a múltiples terapias, mientras no se restaure o se aumente el número de linfocitos T CD4 con la terapia antirretroviral (Highly Active Antiretroviral Therapy, HAART). Esta terapia puede inducir inflamación en las lesiones, como componente del síndrome de reconstitución inmunitario ${ }^{(3,4)}$.

4. En las lesiones no se ven células de Langerhans ${ }^{(8)}$, las presentadoras intraepidérmicas de antígenos, necesarias para la identificación de antígenos virales y de su eliminación natural. ¿Cómo podría inducirse su presencia funcional en las lesiones?

5. No hay tratamientos definidos, lo cual refleja la existencia de múltiples terapias. Es muy importante tener en cuenta que no se deben cambiar las lesiones virales por cicatrices.

\section{CONCLUSIONES}

El molusco contagioso en una infección cutánea viral, más frecuente en la infancia y en sujetos inmunosuprimidos, especialmente en aquellos con infección por HIV.

En pacientes con sida, las lesiones tienen una semiología variada, son más numerosas, alcanzan tamaños mayores, son de mayor duración y recurrentes.

El diagnóstico clínico es fácil y, en caso de duda, puede recurrirse a la biopsia de la lesión o al frotis directo, que demuestran las células típicas del molusco contagioso.

Debido a las características propias del virus, que evade el sistema inmunológico del huésped, con la mayoría de las opciones terapéuticas disponibles se busca generar una reacción inflamatoria que contribuya a la eliminación de la infección. En general, los tratamientos son destructivos, pueden generar dolor e incomodidad en el paciente y en sus padres, razón por la cual muchos médicos prefieren esperar a que el sistema inmunológico elimine por sí solo la infección. Debe educarse a los padres sobre la detección temprana de esta infección, especialmente en niños con alteración de la barrera epidérmica, como aquellos con dermatitis atópica, en los que esta enfermedad es más frecuente.

\section{REFERENCIAS}

1. The Derm101 Team. Molluscum contagiosum [Internet]. A clinical atlas of 101 common skin diseases; 2016. Fecha de consulta: 11 de enero de 2017. Disponible en: https://www.derm101.com/ clinical-atlas/molluscum-contagiosum/all/.

2. Olsen JR, Gallacher J, Piguet V, Francis NA. Epidemiology of molluscum contagiosum in children: A systematic review. Fam Pract. 2014;31:130-6.

3. Fonseca D. Caracterización de la patología dermatológica presente en la población pediátrica infectada con el virus de la inmunodeficiencia humana del Hospital Militar Central atendida durante el año 2006. Rev Asoc Colomb Dermatol. 2008;16:7281.

4. Laxmisha C, Thappa DM, Jaisankar TJ. Clinical profile of molluscum contagiosum in children versus adults. Dermatol Online J. 2003;9:1-9.

5. Chen X, Anstey A, Bugert J. Molluscum contagiosum virus infection. Lancet Infect Dis. 2013;13:877-88.

6. Sanclemente G, Correa LA. Poxvirus que causan enfermedad en los seres humanos. Rev Asoc Colomb Dermatol. 2010;18:67-77.

7. Bergfeld W, Tarbox M. Orf infections and molluscum contagiosum. En: Procop G, Pritt B, editors. Pathology of Infectious Diseases. First edition. Philadelphia: Elsevier; 2015; p.193-205.

8. Smith KJ, Yeager J, Skelton H. Molluscum contagiosum: Its clinical, histopathologic, and immunohistochemical spectrum. Int J Dermatol. 1999;38:664-72.

9. Porras L, Tamayo-Buendía M, Sánchez-Vanegas G. Prevalencia de Infección por VIH en pacientes con patología dermatológica en un centro de referencia nacional, 2005-2006. Rev Salud Pública. 2009;11:613-9.

10. Eleftheriou LI, Kerr SC, Stratman EJ. Diagnosis of atypical molluscum contagiosum: The utility of a squash preparation. Clin Med Res. 2011;9:50-1.

11. Chander R, Jabeen M, Malik M. Molluscum contagiosum-like lesions in histoid leprosy in a 10-yearold Indian boy. Pediatr Dermatol. 2013;30:261-2.

12. Santos-Arroyo AE, Nevares-Pomales OW, Almodóvar PI, Sánchez JL. Molluscum-like lesions in a 12- year-old boy: Challenge. Am J Dermatopathol. 2014;36:984.

13. Negroni R. Cryptococcosis. Clin Dermatol. 2012;30:599-609.

14. Patterson J. Viral diseases. En: Weedon's Skin Pathology. Fourth edition. London: Churchill Li- 
vingstone, Elsevier; 2016; p.717-46.e15.

15. Nguyen HP, Franz E, Stiegel KR, Hsu S, Tyring SK. Treatment of molluscum contagiosum in adult, pediatric, and immunodeficient populations. J Cutan Med Surg. 2014;18:299-306.

16. Bard S, Shiman MI, Bellman B, Connelly EA. Treatment of facial molluscum contagiosum with trichloroacetic acid. Pediatr Dermatol. 2009;26:425-6.

17. Torbeck R, Pan M, de Moll E, Levitt J. Cantharidin: A comprehensive review of the clinical literature. Dermatol Online J. 2014;20:1-9.

18. Moye V, Cathcart S, Morrell DS. Safety of cantharidin: A retrospective review of cantharidin treatment in 405 children with molluscum contagiosum. Pediatr Dermatol. 2014;31:1-5.

19. Hanna D, Hatami A, Powell J, Marcoux D, Maari C, Savard $\mathrm{P}$, et al. A prospective randomized trial comparing the efficacy and adverse effects of four recognized treatments of molluscum contagiosum in children. Pediatr Dermatol. 2006;23:574-9.

20. van der Wouden JC, van der Sande R, van SuijlekomSmit L, Berger M, Butler CC. Interventions for cutaneous molluscum contagiosum. Cochrane Database Syst Rev. 2009;4:CDoo4767.

21. Al-Mutairi N, Al-Doukhi A, Al-Farag S, Al-Haddad A. Comparative study on the efficacy, safety, and acceptability of imiquimod 5\% cream versus cryotherapy for molluscum contagiosum in children. Pediatr Dermatol. 2010;27:388-94.

22. Klinda G, Urban P, Philipp CM, Berlien H-P. 532Nm laser treatment of molluscum contagiosum. Med Laser Appl. 2011;26:172-5.

23. Valentine CL, Diven D. Treatment modalities for molluscum contagiosum. Dermatol Ther. 2000;13:285-9. 